\title{
The Use of Art Therapy in a Patient with Chronic Schizophrenia
}

\author{
Robert Morrow, MD \\ Thomas Jefferson University Hospital
}

Follow this and additional works at: https://jdc.jefferson.edu/jeffjpsychiatry

Part of the Psychiatry Commons

Let us know how access to this document benefits you

\section{Recommended Citation}

Morrow, MD, Robert (1985) "The Use of Art Therapy in a Patient with Chronic Schizophrenia," Jefferson Journal of Psychiatry. Vol. 3 : Iss. 1 , Article 10.

DOI: https://doi.org/10.29046/JJP.003.1.006

Available at: https://jdc.jefferson.edu/jeffjpsychiatry/vol3/iss1/10

This Article is brought to you for free and open access by the Jefferson Digital Commons. The Jefferson Digital Commons is a service of Thomas Jefferson University's Center for Teaching and Learning (CTL). The Commons is a showcase for Jefferson books and journals, peer-reviewed scholarly publications, unique historical collections from the University archives, and teaching tools. The Jefferson Digital Commons allows researchers and interested readers anywhere in the world to learn about and keep up to date with Jefferson scholarship. This article has been accepted for inclusion in Jefferson Journal of Psychiatry by an authorized administrator of the Jefferson Digital Commons. For more information, please contact: JeffersonDigitalCommons@jefferson.edu. 


\title{
THE USE OF ART THERAPY IN A PATIENT WITH CHRONIC SCHIZOPHRENIA
}

\author{
ROBERT MORROW, M.D.
}

\section{INTRODUCTION}

The artistic drawings of psychiatric patients have been of increasing interest to mental health professionals over the last hundred years. In the 1870's Simon speculated on the relationship between the art of psychotics and their illnesses (1). Freud and Jung made observations about the symbolism of art work. By the 1940's Naumberg developed a system of art therapy relying heavily on psychoanalytic theory that is now a therapeutic discipline in its own right (2).

In the inpatient milieu art therapy is commonly offered in conjunction with other therapies that make up the inpatient experience. The art therapist often shares the information gained with the primary therapist when the art work aids in elucidating conflicts, defenses, and thought content that may not have been verbalized by the patient. Rarely does the psychiatrist use art therapy as his primary mode of therapeutic intervention.

\section{CASE REPORT}

The patient, a thirty-eight-year-old male with a longstanding diagnosis of chronic undifferentiated schizophrenia, was admitted to the inpatient psychiatric service after having presented daily for three days to the hospital crisis center complaining of nervousness and insomnia. The patient offered no other substantial information except to say that he had not been taking his medication, thiothixene, $30 \mathrm{mg}$. daily, for the last six months. Reports from the boarding home where he lived revealed that the patient had a three week history of increasing social withdrawal, poor appetite with weight loss, decrease in sleep, and deterioration in personal hygiene. In addition, the patient was noted to have behaved bizarrely, including blank staring for prolonged periods, screaming at the walls, and sleeping on the floor with two sticks across his chest in the shape of a cross. The patient denied these reports. No recent stressors could be documented.

Past psychiatric history was remarkable for several hospitalizations for psychotic episodes in his mid and late twenties. The patient was not hospitalized again until age thirty-five, after which he was hospitalized yearly for exacerbations of schizophrenia. He reported taking antipsychotic medication only briefly following each hospitalization, even though he admitted that the medication did help his chronic "nervousness."

Dr. Morrow is a second-year resident. 
The patient had no history of consistent outpatient followup. He admitted to alcohol abuse from age eighteen to thirty-two, although he had been abstinent for the last six years. There was no history of drug abuse.

Family history was significant for an alcoholic father and a younger sister who had been hospitalized for unknown emotional problems. The patient offered little family or personal developmental data, except to state that he had never felt close to any of his family and had been estranged from them for many years.

The patient completed the eighth grade and had a number of short-lived jobs over the years, usually working as a sign painter or in an art supply store. Prior to admission he had been unemployed for two years. During the past five years the patient stated he had spent most of his time alone, drawing and painting, reading the Bible, and "researching words" in the dictionary.

Mental status examination on admission revealed a well developed male who was unkempt and malodorous. His behavior was guarded and he often appeared to be responding to internal stimuli. His speech was coherent with a normal rate and diminished tonal variation. He spoke only in response to questions. His affect was pleasant but shallow, and he described his mood as "mild." His thought processes were significant for paucity, tangentiality, circumstantiality, and occasional blocking. There was no evidence of thought derailment. He denied auditory and visual hallucinations, suicidal or homicidal ideation. In addition paranoid ideation, ideas of reference, magical thinking, and delusions were suspected, but denied by the patient. He was oriented to person, place, and time. His memory was intact. His concentration was diminished. Abstracting capabilities were idiosyncratic. He appeared to have no insight into the nature of his problem, and his judgment was superficially appropriate.

Physical examination was significant for mildly elevated blood pressure, and a resting tachycardia that resolved within 48 hours. Routine laboratory studies were unremarkable.

During the first week of hospitalization, the patient displayed bizarre behavior, including lying in bed at night fully clothed wearing gloves while placing a long sofa cushion on top of himself. He would often cover his food with napkins and reach under them to eat. Many times he was found anxiously staring into space or at walls, muttering to himself incoherently. When asked to explain his behavior, the patient would say it didn't mean anything, or that he didn't know why he did these things. A significant portion of the patient's day was spent compulsively drawing complex pentagram-like symbols that varied little in design. This appeared to produce a calming effect on the patient and he would refuse to participate in milieu activities in order to continue this behavior. Although it was clear that the drawings had special significance, the patient would not share their meaning, saying only that they relaxed him and that he had to draw 10,000 of them by a certain time.

The patient was initially treated with thiothixene, $40 \mathrm{mg}$. daily, that was titrated up to a dosage of $100 \mathrm{mg}$. of thiothixine daily over a course of three weeks without any significant change in his behavior. He continued to be isolated, anxious and guarded around people, could not care for his personal hygiene and showed no improvement in 
sleep. In individual sessions with his psychiatrist the patient was essentially nonverbal, offering silence or vague monosyllabic answers to questions. Repeated supportive encouragement to verbalize his problems and modify his behavior was met with silent, guarded resistance.

As it became increasingly apparent that the patient expressed himself primarily in a nonverbal manner, it was decided to use art therapy as a means of having the patient express himself and develop a trusting, therapeutic relationship with his psychiatrist.

The patient's first assignment was to draw the conventional person, person of the opposite sex, house, and tree (3). The drawing of a person usually represents the patient himself (4). The patient's drawing, typical of a schizophrenic, had a floating head without a body and vacant eyes representing a loss of ego boundaries and perceptual disorganization (5).

The patient was asked to discuss his drawings with his psychiatrist. For the first time, he anxiously and tentatively began to share his fragmented, menacing and hopeless world. His drawing of a person of the opposite sex was described as "maybe a rassler, maybe somebody mean." This drawing was similar to his first drawing. It had a primarily male head with feminine eyes that may indicate poor reality sense, conflicts with sexuality, and ambivalence towards females (6). The tree drawing, often representative of a patient's affective state (3), had a disorganized, barren and depressed quality to it. In discussing these first drawings, the patient verbally revealed more of himself than he had in the first twenty days of his hospitalization.

A few days later, when asked to draw how life had been going for him, the patient produced what appeared to be a horse, head bent, struggling to pull a cart. "It's some kind of animal pulling a wagon, the kind I used to have as a kid. But the wagon is empty. I don't know why I drew this," the patient explained. This joining of picture and words was in marked contrast to his prior statement that "Everything's okay except for a little nervousness."

As the patient became more comfortable talking about his drawings, he slowly became more at ease discussing other matters with less use of art work. One drawing of his family produced two days worth of very verbal discussion in which he revealed his view of his psychosocial development, perceived sense of early isolation from his family, and family history. Interestingly, the patient was represented by an erased head between the last two heads on the right side of the drawing.

As therapy progressed the patient started initiating contact with the psychiatrist, asking for daily drawing assignments. Gradually the patient's focus in art therapy was shifted to address how others perceived his behavior and how this effected their interaction with him. Slowly the patient began paying greater attention to his personal hygiene, his pentagram drawing became less perseverative and more organized, he appeared calmer, and his sleep improved modestly. During this time his art work became more organized, optimistic, and appropriately detailed. Full human figures appeared. The last picture he drew during his hospitalization is an example of this. "This is a picture of me about a year from now ... I'm in my studio cleaning things up ... I think I'm happy and I'm trying to figure out what to paint; maybe somebody's portrait." Symbolically the patient relates a positive understanding that his progress 
may be slow, but that he can actively participate in the process ("cleaning up"). $\mathrm{He}$ has some uncertainty and still distrusts the world, as evidenced by the figure being drawn on profile and the weapon-like brushes in the figure's hand. However, he shows newfound willingness to interact with others by painting "somebody's portrait."

\section{DISCUSSION}

Art therapy can be a valuable instrument that can be used as an alternative to, or in conjunction with the more traditional inpatient interventions of supportive and reality oriented psychotherapy, milieu therapy, and psychopharmacology $(2,7)$. Initially it may be seen by the patient as less threatening and revealing of himself (8). By working around the resistance to be verbal, art therapy can provide the patient an opportunity to communicate with his therapist. It can aid in more closely duplicating a schizophrenic's primary process view of himself and his world than words would allow (1).

As the case described illustrates, art therapy can act as a catalyst in facilitating verbalization in a nonverbal patient. The formation of a therapeutic alliance between a nonverbal patient and his therapist is made easier through art therapy by showing the patient a willingness on the part of the therapist to understand him on his own terms. Art therapy may also relieve the monotony, boredom, and frustration often encountered when employing conventional "talk" therapy in nonverbal patients. By circumventing this, art therapy fosters the trusting relationship that is necessary in order to bring about change in the patient.

Finally, art therapy can be helpful in monitoring the patient's progress in the hospital and act as confirmatory clinical evidence of change $(8,9)$. Although it is important not to discount the beneficial effects that medication, the milieu, and other variables may have played in the recovery of the patient described, it appears clear that art therapy played a significant role in facilitating a positive change in his behavior and his therapy.

\section{REFERENCES}

1. Arieti S: Interpretation of Schizophrenia, 2nd edition. New York, Basic Books, 1974.

2. Wadeson H: Art Psychotherapy. New York, Wiley and Sons, 1980

3. Hammer EF: The Clinical Application of Projective Drawings, 5th edition. Springfield IL, Charles C. Thomas, 1978

4. Machover K: Personality Projection in the Drawing of the Human Figure, 10th edition. Springfield IL, Charles C. Thomas, 1978

5. Hozier AQ: On the breakdown of the sense of reality: a study of the spatial perception in schizophrenia. J Consul Psych 23: 185-194, 1959

6. Weiner IB: Psychodiagnosis in Schizophrenia. New York, John Wilen, 1966

7. Naumberg M: Dynamically Oriented Art Therapy: It's Principles and Practice. New York, Grune and Stratton, 1966

8. Kramer ES, Jage A-C: The use of art in assessment of psychotic disorders: changing perspectives. Art Psychother 11: 197-201, 1984

9. Amos SP: The diagnostic, prognostic, and therapeutic implications of schizophrenic art. Art Psychoth 9: 131-143, 1982 